\section{Questión}

Periodismo / Comunicación ISSN 1669-6581

Una radio web universitaria: RadioPerio

Equipo de gestión de RadioPerio

Question/Cuestión, Vol. 2, № 66, Agosto 2020

ISSN 1669-6581

https://perio.unlp.edu.ar/ojs/index.php/question/index

IICom-FPyCS-UNLP

\title{
UNA RADIO WEB UNIVERSITARIA: RADIOPERIO
}

\section{A UNIVERSITY WEB RADIO: RADIOPERIO}

\author{
Equipo de gestión RadioPerio \\ @RadioPerio
}

\section{Resumen}

El trabajo recorre la historia de la emisora web de la Facultad de Periodismo y Comunicación Social de la Universidad Nacional de La Plata.

\section{Palabras clave}

Radio web, Radios universitarias

\section{Abstract}

The work covers the history of the web station of the Faculty of Journalism and Social Communication of the National University of La Plata. 
IICom (Instituto de Investigaciones en Comunicación) 


\section{Keywords}

Web Radio, University Radios

Corría febrero de 2008 y en una reunión de cátedra de Radio I, en medio del abrumador calor platense, el debate entre les profesores era qué hacer con las prácticas, cómo acercar a les estudiantes a las radios sin tener que ir muy lejos, ya que las experiencias previas quedaron muy a contramano y dificultaron el acceso a ellas.

Entre idas y vueltas, surgió la idea de tener un medio propio, perteneciente en su totalidad a la Facultad de Periodismo y Comunicación Social. Que no sólo sirviera como espacio para las prácticas de les alumnes, sino también para transformarlo en un campo donde profesionales puedan desarrollarse. Este pasó a ser su principal objetivo, convertir el medio soñado en una herramienta con características mixtas, donde lo profesional y pedagógico se encuentren en un mismo espacio. Además, se buscaba algo nuevo, algo con lo que la Facultad nunca había contado y con lo que pudiera marcar diferencia.

También se pensaba en la voz del alumnado como protagonista, que no fueran les profesores quienes debían hablar, sino que su labor fuera la de guiar a les estudiantes para dar frente al desafío de tomar la palabra; de decir lo que creían era necesario que el público escuche.

De esta característica nace la importancia de tener un medio propio: al ser una Facultad en la que suceden tantas cosas, el guardarlas para sí misma no sería lo correcto.

Pensando en la pluralidad de voces tantas veces defendida, la existencia de un medio de comunicación que pueda hablar desde lo propio y no ser hablado por 
intereses ajenos se transforma en un punto esencial; un objetivo que era necesario saldar.

A su vez, se buscaba no sólo la participación de practicantes y alumnes, sino también de toda la comunidad de la Facultad: RadioPerio no fue pensada como un ente individual, reducido únicamente a una materia, sino como un colectivo que se nutre de todes les que lo conforman.

En un principio, se dificultó encontrar un espacio físico, pero con la mudanza de Periodismo a su nueva sede en 63 y diagonal 113, el edificio original ubicado en 44 entre 8 y 9 quedó disponible para poder llevar adelante el proyecto. Así, el 10 de octubre de 2009, comenzó a transmitirse por internet "RadioPerio", llevado adelante por sus mentes creadoras: les docentes del Taller de Producción Radiofónica I que, junto a sus alumnes, aportaron el contenido para aquellas transmisiones. También hubo algunes estudiantes valientes que se acercaron con sus propios programas.

Sin fines de lucro, y con un objetivo basado netamente en el aprendizaje y en dar oportunidades, cada vez más gente fue uniéndose y así comenzó a crecer este medio.

Ya en el año 2011, RadioPerio empezó a funcionar en la sede "Néstor Kirchner" de la Facultad de Periodismo. Allí surgió la idea de aprovechar las diferentes producciones y actividades que se realizaban en nuestra unidad académica. De esta manera, tuvieron lugar no sólo las prácticas preprofesionales de les alumnes de las materias de Radio, sino también las transmisiones de diferentes congresos, seminarios, charlas y otras actividades que se iban dando dentro del ámbito institucional. De esta forma, el espectro temático fue en aumento y la diversidad de programación, como la creatividad 
de la misma, también. Se propiciaba así un espacio de expresión en respeto de ideas propias y ajenas.

RadioPerio se consolidó entonces como un espacio democrático, donde aquel o aquella que quisiera aportar su voz pudiera hacerlo, pero, al mismo tiempo, estimulando la reflexión acerca de las responsabilidades que se deben tener tanto a nivel personal como global al momento de implicarse en el ejercicio de la comunicación radiofónica.

Hoy RadioPerio continúa con estos ideales, manteniendo su objetivo principal: ser un punto de conexión entre estudiantes, futures profesionales y graduades, donde pueden desarrollarse libremente y encontrarse en el mundo de la radio conjugando la práctica con la experiencia de convertir el espacio en fuente de información y difusión.

Actualmente su grilla se conforma por varios programas que son realizados desde el aislamiento obligatorio y que hacen al cotidiano del medio esperando sumar nuevas voces a un lugar que no tiene derecho de admisión y que sueña, alguna vez, poder lograr el anhelo de una antena propia para seguir así garantizando tanto la producción de contenidos como el derecho y acceso a la información. 